\title{
High-Resolution MRI for Evaluation of Ventriculostomy Tubes: Assessment of Positioning and Proximal Patency
}

\author{
(D) A.M. Blitz, (DP.P. Huynh, (DL.W Bonham, (D) S.K. Gujar, (DD.E. Sorte, (D) A. Moghekar, (D) M.G. Luciano, and (DD. Rigamonti
}

\begin{abstract}
BACKGROUND AND PURPOSE: Imaging evaluation of ventriculostomy tubes, despite the frequency of malfunction, has remained inadequate due to the absence of a systematic way of assessing the catheter itself. In this retrospective review, we assessed the utility of high-resolution 3D MR imaging techniques, including CISS and volumetric interpolated breath-hold examination sequences, in the evaluation of ventriculostomy catheters.
\end{abstract}

MATERIALS AND METHODS: We performed a retrospective review of 23 clinical MR imaging cases of shunted hydrocephalus spanning a 3-year period, all depicting ventriculostomy catheters. The MR imaging examinations included isotropic CISS and volumetric interpolated breath-hold examination sequences performed with and without contrast. These were independently evaluated by 2 neuroradiologists with respect to the catheter course, side hole position, relationship of the side holes to the ventricles, patency, and the presence or absence of intraluminal debris.

RESULTS: The catheter tip was best seen on isotropic CISS sequences reformatted in an oblique plane, and side holes were visualized as CSF signal defects along the catheter wall in 10/23 (43\%) cases. The relationship of the catheter side holes to the ventricles was seen in $47 \%$ of cases and was best visualized on the coronal CISS sequences. Catheter patency was confirmed in $12 / 23$ (52\%) cases, while the other $48 \%$ were notable for $\mathrm{T} 2$ hypointense filling defects compatible with luminal obstruction. Enhancement of some of these filling defects on imaging is suggestive of choroid plexus ingrowth rather than debris.

CONCLUSIONS: High-resolution 3D MR imaging using isotropic CISS sequences allows systematic evaluation of catheter positioning, patency, and potential etiologic differentiation of filling defects when shunt dysfunction is suspected.

ABBREVIATION: VIBE = volumetric interpolated breath-hold examination

V entriculostomy tube placement has been performed for CSF diversion since the early $1960 \mathrm{~s}^{1}$ and is one of the most commonly performed neurosurgical procedures, accounting for approximately $\$ 1$ billion in health care costs per year in the United States. ${ }^{2}$ CSF shunt dysfunction is an extremely common

Received March 5, 2019; accepted after revision October 2.

From the Department of Radiology (A.M.B.), University Hospitals, Case Western Reserve University; Departments of Radiology and Radiological Sciences (A.M.B. P.P.H., L.W.B., S.K.G.), Neurology (A.M.), and Neurosurgery (A.M.B., M.G.L., D.R.), Johns Hopkins Medical Institutions, Baltimore, Maryland; and Department of Radiology (D.E.S.), University of New Mexico, Albuquerque, New Mexico.

Drs Blitz and Rigamonti have previously ( $>24$ months prior) received research funding from Aesculab (Dr Rigamonti was the Principal Investigator). Dr Blitz receives research support (unrelated) via AVERT, FAIN U01DC013778 (NewmanToker is the Principal Investigator).

Please address correspondence to Ari M. Blitz, MD, University Hospitals, Case Western Reserve University, Diagnostic Radiology, Division of Neuroradiology, 11100 Euclid Ave., BSH 5056, Cleveland, OH 44106; e-mail: ari.blitz@uhhospitals.org

Indicates article with supplemental on-line video.

http://dx.doi.org/10.3174/ajnr.A6320 clinical problem, with failure rates as high as $40 \%$ in the first year and $50 \%$ after 2 years, ${ }^{3}$ with about $50 \%$ of patients requiring at least 1 shunt revision during their lifetime., ${ }^{4,5}$ Although some of these failures relate to infection and overdrainage $3.6 \%$ and $7.6 \%$, respectively) ${ }^{6}$ and are readily diagnosed clinically, mechanical failures, despite apparent adequate anatomic placement, also contribute to the overall failure rate. When shunt failure is suspected clinically, the site of obstruction may be proximal to the shunt valve (or reservoir) or in the distal tubing.

Despite the prevalence of shunt failure, conventional imaging studies are often inadequate to provide a diagnosis if they find no signs of obstruction..$^{7-10}$ The radiographic "shunt series" identifies a cause of shunt malfunction in $<10 \%$ of pediatric cases and even less frequently in adults, suggesting the low diagnostic utility of this technique. ${ }^{11,12} \mathrm{CT}$, while more sensitive in assessing ventricular size and grossly determining intracranial catheter position, does raise concerns for radiation exposure, especially in pediatric patients, ${ }^{13,14}$ who may require repeat imaging during 
their lifetimes. Nuclear medicine radionucleotide studies can also be used but require shunt access and entail radiation exposure as well.

MR imaging is not typically performed in the evaluation of shunted hydrocephalus in children, given its lengthy imaging time and potential need for sedation. ${ }^{15}$ Moreover, even when MR imaging is performed in a patient with shunted hydrocephalus,

Baseline patient demographic data

\begin{tabular}{lc}
\hline \multicolumn{1}{c}{ Demographic } & Statistic (No.) (\%) \\
\hline Age (mean) (range) (yr) & $47.9(32-74)$ \\
Sex & $10(43.5)$ \\
Male & $13(56.5)$ \\
Female & \\
Indication for VP shunting & $11(47.8)$ \\
Obstructive hydrocephalus & $7(30.4)$ \\
Congenital hydrocephalus & $3(13.0)$ \\
Communicating hydrocephalus & $2(8.7)$ \\
Pseudotumor cerebri & \\
Indication for imaging & $11(47.8)$ \\
Concern for shunt malfunction & $6(26.1)$ \\
Alarming neurologic symptoms & $6(26.1)$ \\
Routine follow-up & \\
Type or brand of shunt (per chart review) & $8(34.7)$ \\
Programmable shunts & $6(26.1)$ \\
Strata ${ }^{a}$ & $2(8.7)$ \\
Unspecified & $7(30.4)$ \\
Nonprogrammable shunts & $1(4.3)$ \\
Codman & $1(4.3)$ \\
Raimondi & $5(21.7)$ \\
Unspecified & $8(34.7)$ \\
Unspecified/no information found &
\end{tabular}

Note:-VP indicates ventriculoperitoneal.

${ }^{a}$ Medtronic, Minneapolis, Minnesota. the catheter patency, side hole position, and entire intracranial course may not be systematically evaluated by conventional sequences.

MR phase-contrast imaging can be performed to determine shunt flow, ${ }^{16-19}$ but it is technically challenging and does not define the anatomic position of the catheter or allow assessment of the catheter lumen itself when flow is not detected. High-resolution techniques, including CISS and volumetric interpolated breath-hold examination (VIBE) sequences, are used for evaluation of small structures such as cranial nerves, given their high spatial resolution. ${ }^{20-23}$ These techniques can also be used in the MR imaging of hydrocephalus. ${ }^{24,25}$

At our center, dedicated imaging protocols for the evaluation of patients with hydrocephalus include high-resolution imaging. Such imaging is typically through the cerebral aqueduct, though imaging tailored to the evaluation of the ventriculostomy tubes is also available to the clinician. In the current study, we retrospectively analyzed the position and patency of ventriculostomy catheters on clinical MR imaging studies. We reviewed clinical MR imaging examinations performed for hydrocephalus to determine the value of MR imaging in the assessment of the ventriculostomy catheter itself. We hypothesized that detailed information about the ventriculostomy catheter could be gleaned from high-resolution, specialized MR imaging techniques.

\section{MATERIALS AND METHODS}

Approval for this study was obtained from the Johns Hopkins Institutional Review Board. A retrospective sample of convenience, including all available clinical cases spanning a 3-year period at our institution, was identified. Data were collected in adherence with the applicable Health Insurance Portability and Accountability Act regulations. Twentythree clinical MR imaging examinations were selected from clinical cases featuring ventriculostomy catheters due to concern for hydrocephalus or shunt complications, following placement in a variety of disorders including hydrocephalus and pseudotomor cerebri. Baseline patient data are shown in the Table.

The MR imaging examinations included routine brain imaging sequences and high-resolution isotropic CISS and VIBE sequences with and without contrast and were typically performed on a $3 \mathrm{~T}$ Trio or Verio scanner (Siemens, Erlangen, Germany). Cases were excluded if CISS and VIBE sequences were not performed. A typical examination included standard sequences (sagittal MPRAGE/T1, axial T2, axial FLAIR, postcontrast T1) plus isotropic CISS sequences (TR, $5.88 \mathrm{~ms}$; TE, $2.7 \mathrm{~ms}$; FOV, $16 \mathrm{~cm}$; matrix size, $320 \times 320$ ) without or before and after intravenous
FIG 1. 3D high-resolution isotropic CISS MR imaging sequence acquired in the sagittal plane demonstrates CSF signal throughout a patent ventriculostomy tube. Images were reconstructed post hoc in the sagittal oblique $(A)$, axial $(B)$, and coronal $(C)$ planes. 


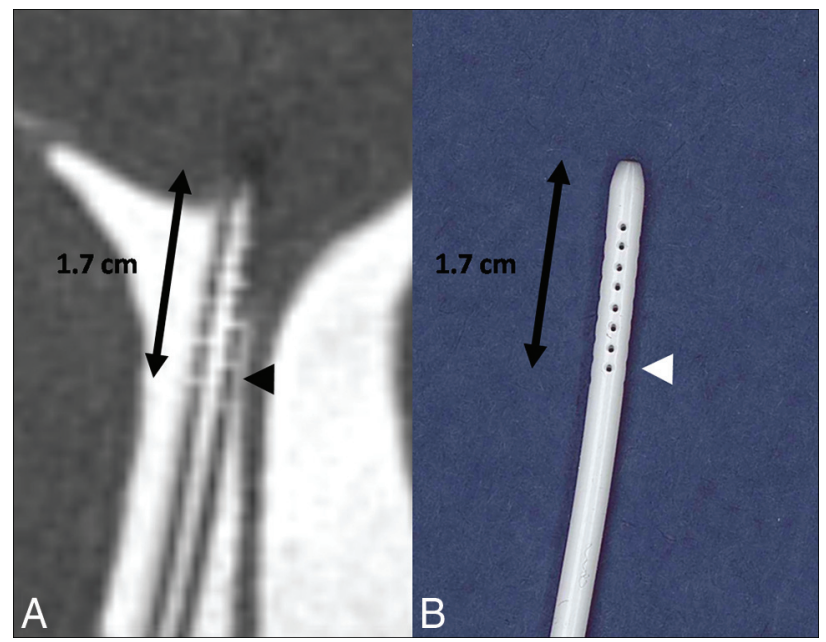

FIG 2. A, Isotropic CISS demonstrates a right-parietal-approach catheter with the tip extending just beyond the frontal horn of the right lateral ventricle. The side holes are seen as fluid-filled defects in the proximal aspect of the catheter extending to $1.7 \mathrm{~cm}$ from the tip (arrowhead). B, A photograph of a corresponding ventriculostomy catheter sample depicts the same relationship of side holes to the tip of the catheter.

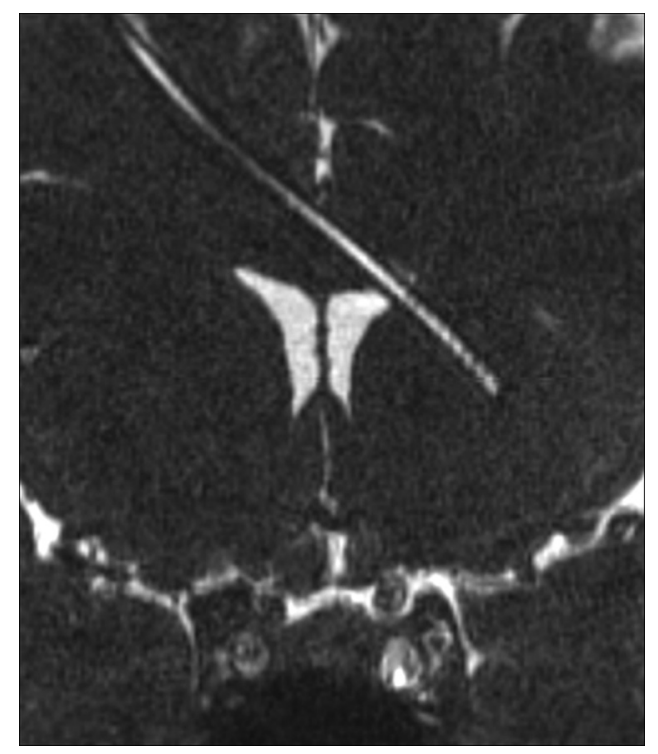

FIG 3. Coronal isotropic CISS demonstrates the tip of the ventriculostomy catheter passing beyond the left lateral ventricle. The lumen is fluid-filled.

gabdobenate dimeglumine (MultiHance; Bracco Diagnostics, Princeton, New Jersey; $0.1 \mathrm{mmol} / \mathrm{kg}$ ) or gadopentetate dimeglumine (Magnevist; Bayer HealthCare Pharmaceuticals, Wayne, New Jersey; $0.1 \mathrm{mg} / \mathrm{kg}$ ), and isotropic T1 VIBE out-of-phase sequences with fat saturation after intravenous contrast (TR, $11.6 \mathrm{~ms}$; TE, $4.3 \mathrm{~ms}$; FOV, $16.9 \times 21 \mathrm{~cm}$; matrix size, $288 \times$ 232). The voxel size was typically $0.5 \mathrm{~mm}$ except in 2 cases in which the voxel sizes were 0.6 and $0.7 \mathrm{~mm}$. Seven of 23 examinations were requested specifically for ventriculostomy tube evaluation and included dedicated phase-contrast imaging through the catheter lumen (TR, $69.6 \mathrm{~ms}$; TE, $10.8 \mathrm{~ms}$; FOV,
$8 \mathrm{~cm}$; matrix, $320 \times 256)$ in addition to high-resolution imaging along the intracranial course of the catheter. The visualized portion of the catheter was assessed on the remainder of the examinations. With these imaging modalities it is possible to view, when captured, the side hole location, tip location, and catheter patency as well as the content of the catheter lumen.

Two neuroradiologists (1 fellow [D.E.S.] and 1 Certificate of Added Qualification-certified neuroradiologist [A.M.B.] with 10 years of experience) retrospectively evaluated the MR imaging examinations with respect to 3 factors: proximal (tip) position/ catheter course, side hole position, and the relationship of the side holes to the ventricular lumen; the catheter reservoir if visible, and the presence or absence of debris in the catheter lumen. The visibility of the side holes was rated as 0 for nonvisualization, 1 for partial visualization, and 2 for complete visualization. The neuroradiologists evaluated the patency of the catheter lumina. Patency was defined as fluid filling the catheter without obstruction. Additionally, the presence or absence of internal debris was documented. Each examination was reformatted in various obliquities to best demonstrate the catheter position. Disagreements were resolved by consensus.

\section{RESULTS}

\section{Catheter Visualization}

The catheter tip was visualized in all selected patients. The relationship of the catheter tip to anatomic structures was best visualized on isotropic CISS sequences reformatted in an oblique plane (Fig 1).

\section{Catheter Position: Side Holes}

Despite their small size, the side holes of the catheter were visualized completely (a score of 2 ) in $9 / 23$ cases (39.1\%). The side holes are seen as CSF signal defects along the proximal portion of the ventriculostomy catheter, extending $1.7 \mathrm{~cm}$ from the tip (Fig 2 ). The side holes of the catheter were partially visualized (a score of 1 ) in $1 / 23$ cases $(4.3 \%)$. In both the completely and partially visualized side holes, their relationship to the ventricles was well seen ( $47 \%$ of cases). When the side holes were not visualized this was usually due to the proximal portion of the catheter not being included in the FOV or, in 1 case, due to the larger voxel size.

Of the 7 cases in which a catheter evaluation was specifically requested, 4 (57.1\%) were found to have radiographic findings concerning for malfunction, which was confirmed in the operative note. Of the other 3 cases in which tube evaluation was requested, 2 were for routine monitoring, whereas 1 showed no evidence of shunt malfunction. Catheter side holes were visualized in 4 of the 7 cases.

\section{Catheter Position: Relation to the Ventricles}

The relationship of the proximal catheter side holes and ventricular structures was subjectively best visualized on coronal CISS images (Fig 3). Catheter side holes were often seen in the frontal horns of the lateral ventricles. The relationship of the catheter tip to the foramen of Monro, septum pellucidum, and corpus callosum was depicted on coronal CISS images (Fig 4). 


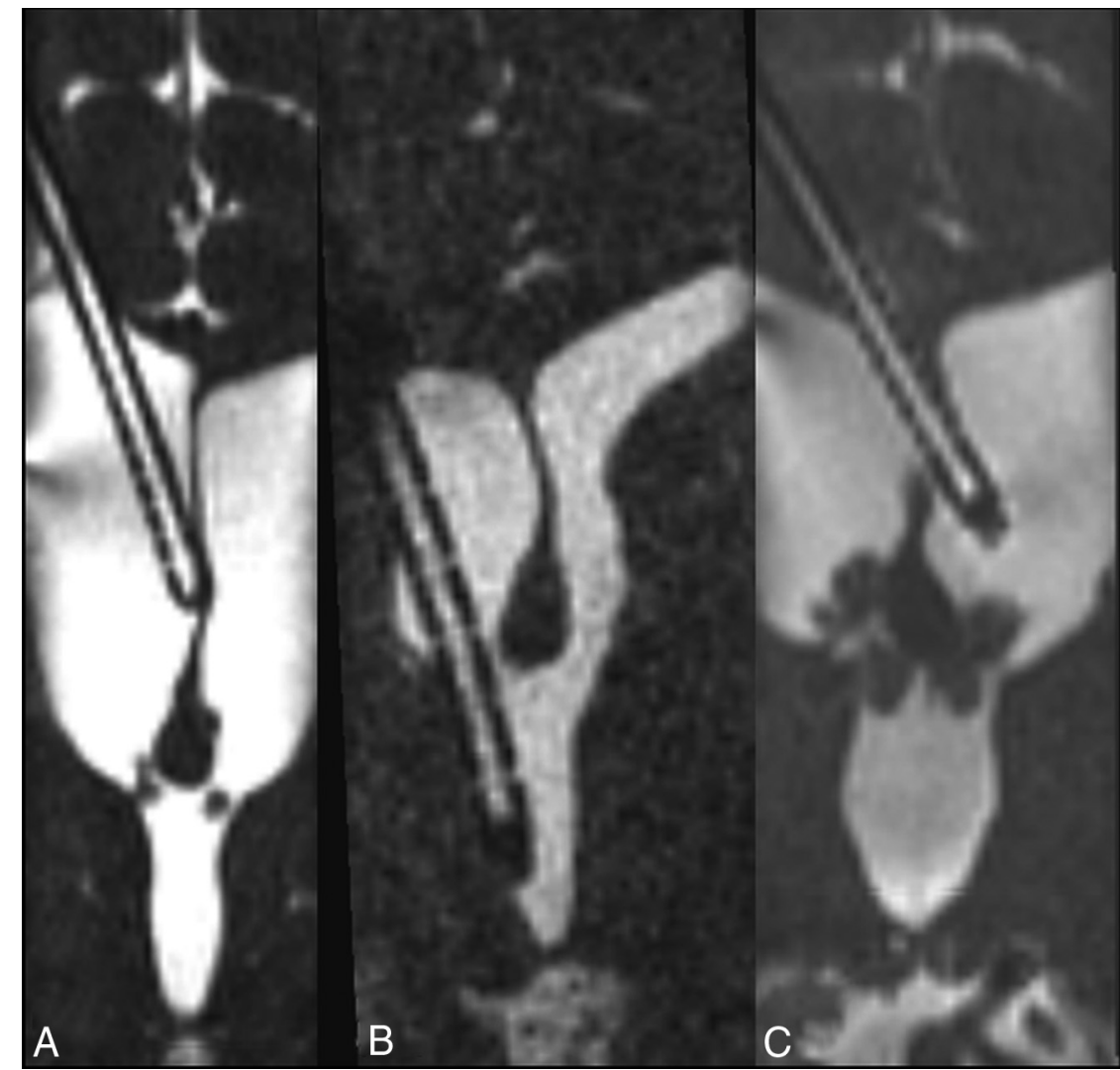

FIG 4. Coronal CISS images from 3 patients demonstrate the position of the catheter tip with precision with respect to the surrounding structures. $A$, The ventriculostomy catheter abuts the septum pellucidum. $B$, The ventriculostomy catheter traverses the foramen of Monro to terminate in the third ventricle. $C$, The ventriculostomy catheter pierces the septum pellucidum, crossing the midline, in a third patient.
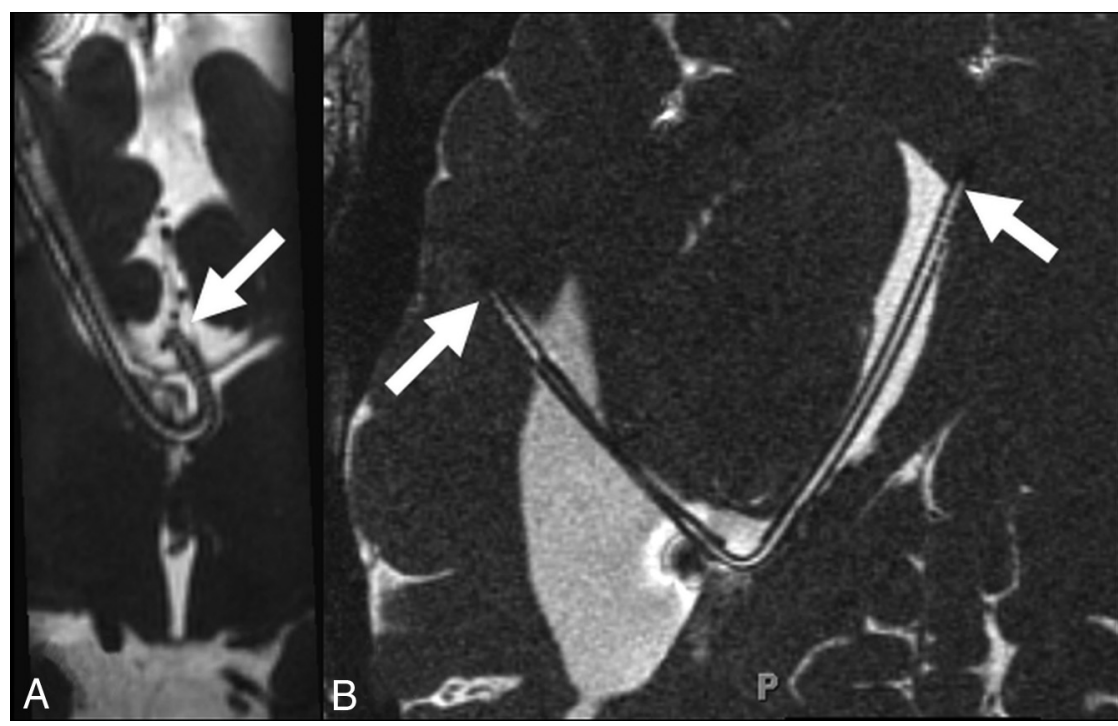

FIG 5. A, Coronal CISS in a patient with callosal dysgenesis demonstrates the curvilinear path of the ventriculostomy catheter with the tip in the interhemispheric fissure. $B$, Axial oblique CISS in a patient with previous obstruction at the posterior body of the lateral ventricle demonstrates tubing extending from the right frontal horn (left-pointing arrow) into the temporal horn of the lateral ventricle to terminate in the periventricular region (right-pointing arrow).

\section{Catheter Configurations}

Some catheters had unusual configurations and required additional postprocessing to be adequately visualized on MR imaging (Fig 5). Reconstruction of isotropically acquired images at the workstation by the radiologist allowed depiction of most or the entirety of the intracranial portion of the catheter course. The catheter reservoir was also seen in $14 / 23$ patients (60.9\%). The detailed internal structure of the reservoir and its connection to the catheter were also seen on highresolution imaging (Fig 6).

\section{Catheter Patency: Presence of Debris or Choroid Plexus Ingrowth}

The catheter lumina were determined to be patent in $12 / 23$ ventriculostomy tubes (52\%) by identification of CSF signal intensity throughout the lumen. The remaining catheters $(11 / 23,48 \%)$ demonstrated T2-hypointense filling defects within the lumen, compatible with internal obstruction, which varied widely in volume and distribution. Of these filling defects, postcontrast CISS and MPRAGE imaging allowed differentiation between debris, which showed no enhancement, and choroid plexus ingrowth, which demonstrated enhancement (Figs 7 and 8).

\section{Global Characterization of Shunt Function}

To better evaluate the sensitivity of imaging for shunt dysfunction, we reviewed each patient's operative note (if available) after shunt insertion. Of the 23 cases, 11 went to the operating room and were found to have nonfunctioning shunts. Notably, of the 11 cases clinically suspected of having shunt malfunction, 8 had radiographic findings supportive of the diagnoses, with the other 3 cases were found to have hydrocephalus despite a patent shunt.

\section{DISCUSSION}

To our knowledge, high-resolution MR imaging studies have never been reported as a tool to specifically evaluate the ventriculostomy catheter. This study demonstrates that high-resolution MR imaging can visualize, with 


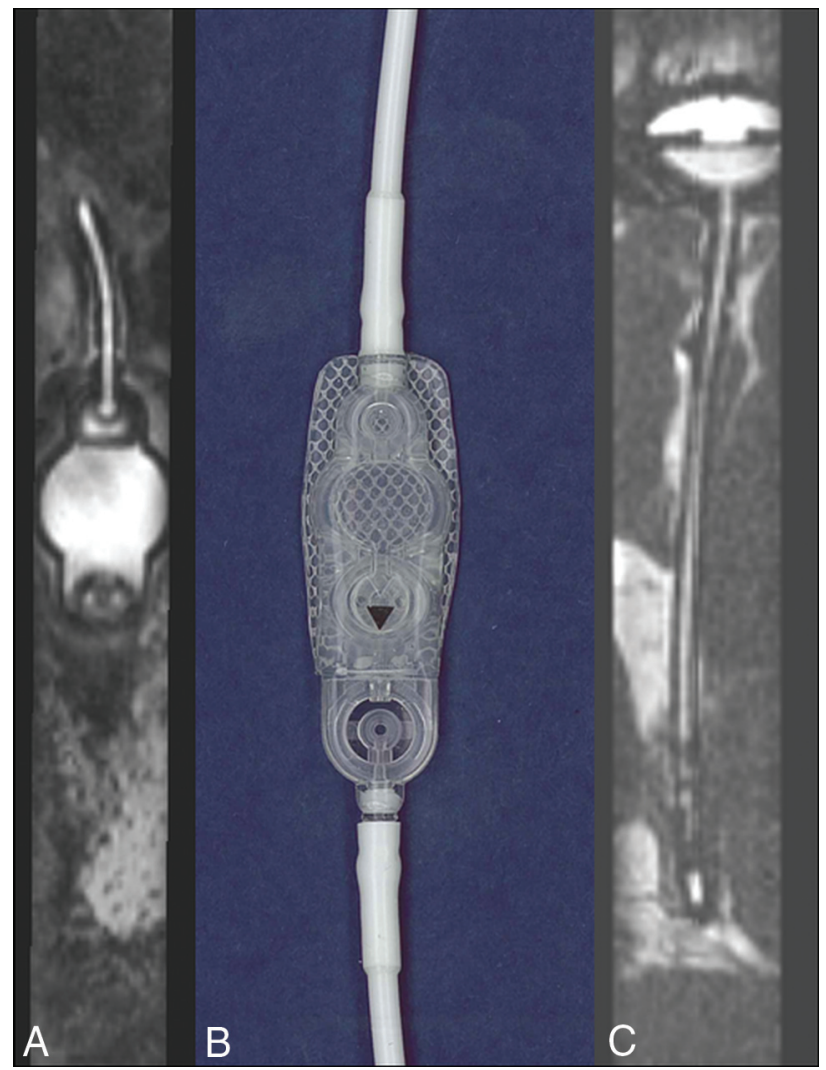

FIG 6. The detailed structure of the ventriculostomy tube and shunt reservoir can be evaluated in detail, particularly when the device does not contain metallic components. A, Sagittal oblique CISS through the extracranial component of the shunt device demonstrates the fluid-filled shunt reservoir corresponding to the sample (B) provided by the manufacturer Strata, Medtronic (Minneapolis, Minnesota). In another patient, the intracranial extent of the ventriculostomy tubing is seen extending to the shunt reservoir, of which the internal structures are visible.

precision, the placement of implanted tubes and can sometimes demonstrate the location of the side holes, potentially of use when it is not clear whether the tube is in actuality draining the intended cavity. From this retrospective review, we found that using high-resolution isotropic CISS sequences in the MR imaging assessment of hydrocephalus allowed visualization of the catheter tip, catheter course, side holes, the relationship of the side holes to the ventricles, and the presence or absence of debris within the lumen. The catheter course, though sometimes unusual (Fig 5), was viewed using post hoc reconstruction of isotropically acquired images in various obliquities. Additionally, we report that filling defects within the proximal catheter may be visualized and potentially characterized with high-resolution MR imaging when shunting dysfunction is suspected or when revision is contemplated.

One of the primary reasons for long-term shunt failure has been reported to be choroid plexus ingrowth. At the time of shunt removal, massive intraventricular hemorrhage can occur due to traction of the ingrown choroid plexus. ${ }^{26}$ Chambi and Hendrick ${ }^{27}$ first described a neurosurgical technique for shunt revision consisting of inserting a metal cannula into the ventriculostomy tube followed by unipolar diathermy to the distal end, believed to

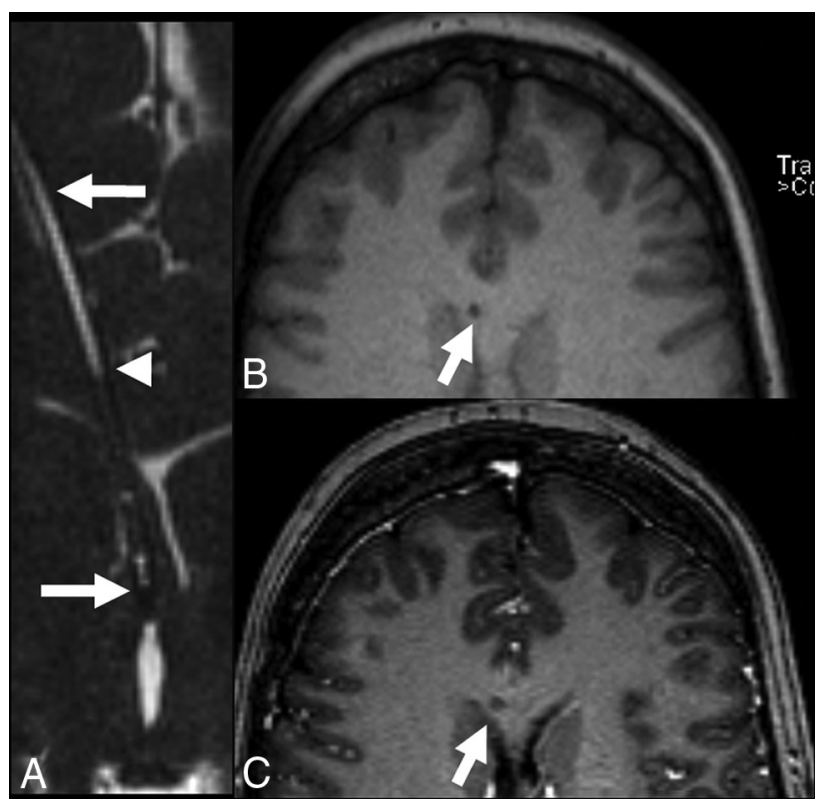

FIG 7. Shunt failure. While this case does not feature hydrocephalus, patients may have ventriculoperitoneal shunt placement for a variety of indications, including pseudotumor cerebri, where ventricles are narrowed rather than dilated, as well as cases involving multiple catheters, in which the development of obstructive hydrocephalus is impeded even if 1 of the shunts is partially occluded by debris. A, Axial oblique reconstructed CISS demonstrates the tip of the ventriculostomy tube (right-pointing arrow) extending peripherally through the frontal lobe (left-pointing arrow). CSF is not seen in the proximal catheter (compare with Fig 3) to the point marked with an arrowhead. B, Axial precontrast MPRAGE demonstrates the catheter extending through the corpus callosum. $C$, Axial postcontrast MPRAGE demonstrates no change in intensity, suggesting debris.

lyse adhesions to the ventricular ependyma or choroid plexus. Multiple variations of this technique have subsequently been described. However, this technique is not without its complications, as described by Handler, ${ }^{28}$ because charring of the catheter (with potential injury to the adjoining brain) has been reported.

Prior techniques for imaging evaluation of ventriculostomy tube patency have largely come from the field of nuclear medicine (eg, a tracer is injected followed by serial imaging over the site of injection and along the expected track of the catheter to document the flow of the radiotracer). In some cases, the task of evaluation of tube patency is further complicated by lack of accessibility. This is the case with tubes that drain directly from 1 portion of the ventricular system or subarachnoid space such as ventriculo-ventricular catheters (Fig 5). In such cases, assessment of luminal patency by MR imaging may afford the only noninvasive means of postoperative results if symptoms persist or recur. Furthermore, contrastenhanced imaging may help differentiate debris and choroid plexus ingrowth in the setting of contemplated removal of a ventriculostomy tube, potentially allowing appropriate surgical planning and application of preemptive electrocautery through the catheter lumen.

Delayed intracranial hemorrhage at the site of catheter placement is an uncommon-but-severe complication of 


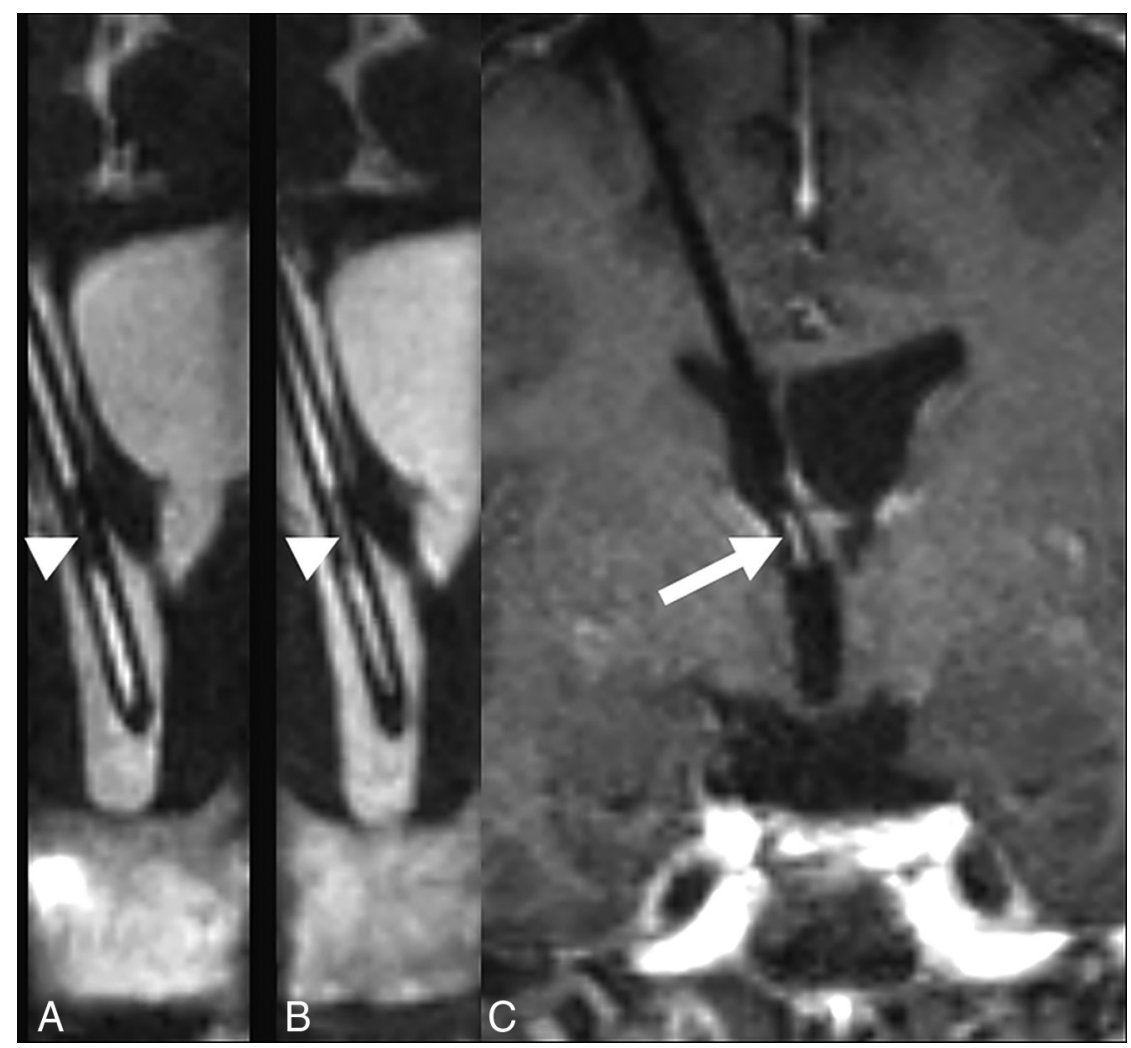

FIG 8. The ingrowth of the choroid plexus into the shunt catheter may significantly increase the risk of hemorrhage during shunt removal. A, Precontrast coronal CISS demonstrates a filling defect within the ventriculostomy tube. $B$, Postcontrast CISS demonstrates an increase in intensity due to enhancement of material filling the midportion of the catheter, suggesting choroid plexus ingrowth. C, Coronal postcontrast MPRAGE demonstrates corresponding hyperintensity, though the relationship to the catheter lumen is not as clear.

ventriculoperitoneal shunt placement and is associated with predisposing factors, including degenerative vascular change and puncture of the choroid plexus. ${ }^{29}$ Similarly, intracranial hemorrhage and intraventricular hemorrhage have long been documented as potential complications of shunt removal and are commonly attributed to the disruption of the choroid plexus that has grown around and into the catheter. ${ }^{30-33}$ A retrospective review of 35 pediatric patients with a total of 52 shunt revisions found that $25 \%$ of the revisions resulted in intraventricular hemorrhage, though only $2 \%$ of such revisions were deemed clinically relevant, resulting in $>5 \mathrm{~mL}$ of blood. ${ }^{34}$ Given the risk of intraventricular hemorrhage and the time to subsequent shunt revision, ${ }^{31,34}$ it may be helpful for surgeons to visualize the presence of choroid plexus ingrowth to assess the risk of hemorrhage following shunt removal and to guide surgery.

We acknowledge that this study has limitations. Given the small sample size of 23 cases, larger studies are needed to verify and generalize our findings. With a limited sample size and heterogeneous comparison images (a mix of alternative MR imaging protocols and CT), calculation of sensitivities and specificities for detecting features such as the catheter lumen or tip is of limited clinical and scientific value. Additionally, in this initial retrospective review, we analyzed data available without respect to manufacturer, tube caliber, or size of the side holes. The side hole position varies by catheter type, and not all devices were placed at our hospital, making inference of the overall position by side hole positioning difficult. It is possible that future prospective work on this topic that controls for these shunt characteristics may allow clarification of which factors, including side hole size and catheter position, are most important for visualization.

Furthermore, our initial work on the nature of filling defects in the catheter lumina is limited because histopathologic proof is not available for our cases of explanted catheters. Histologic confirmation is not easily achievable because withdrawing such catheters carries a substantial risk of intracranial hemorrhage. Thus, neurosurgeons often cauterize off the catheter lumen when choroid plexus ingrowth is suspected. If high-resolution MR imaging sequences can help differentiate choroid plexus ingrowth from intraluminal debris, we believe these findings can help guide the neurosurgeon's decisions in shunt-revision procedures. If this proves true, histologic characterization of intraluminal debris will be possible, but the ability to characterize choroid plexus ingrowth will likely be precluded by the routine application of cautery to prevent intracranial hemorrhage. Finally, the clinical significance of intraluminal debris remains unknown. We suspect that there is a continuum of luminal obstruction that results in a spectrum of clinical manifestations for the patient, but this hypothesis will require further research in larger cohorts to better study its potential clinical consequences.

Future research should include determination of the sensitivity and specificity for these techniques in detecting the sites of clinical shunt malfunction. Additionally, it would be worthwhile to compare MR imaging results and operative findings to better evaluate the utility of this technique in differentiating debris and choroid plexus ingrowth. In-corporating these high-resolution sequences has the potential to aid in neurosurgical planning. Because the treatment of catheter obstruction or malpositioning is surgical revision, greater diagnostic accuracy in imaging evaluation can guide the surgeon in evaluating the best approach. Whether high-resolution visualization of the catheter tip proves to be of additional value compared with a lower resolution technique such as CT remains to be determined. Nevertheless, these techniques could be particularly useful in the setting of a clinical presentation of shunt dysfunction with multiple intracranial catheters. As shown in the On-line Video, high-resolution MR imaging sequences provide additional detail beyond that of standard head CT, which may equip both radiologists and their 
clinical colleagues with useful information when assessing shunt function.

\section{CONCLUSIONS}

High-resolution 3D MR imaging using isotropic CISS sequences allows systematic evaluation of ventriculoperitoneal catheter positioning and patency and differentiation of filling defects when shunt dysfunction is suspected. Systematic evaluation of the catheter, in turn, may allow improved diagnosis of shunt failure and, potentially, assessment for hemorrhage risk following shunt removal, thereby guiding surgical effort.

\section{REFERENCES}

1. Aschoff A, Kremer P, Hashemi B, et al. The scientific history of hydrocephalus and its treatment. Neurosurg Rev 1999;22:67-93; discussion 94-95 CrossRef Medline

2. Patwardhan RV, Nanda A. Implanted ventricular shunts in the United States: the billion-dollar-a-year cost of hydrocephalus treatment. Neurosurgery 2005;56:139-44; discussion 144-45 CrossRef Medline

3. Browd SR, Ragel BT, Gottfried ON, et al. Failure of cerebrospinal fluid shunts, Part I: obstruction and mechanical failure. Pediatr Neurol 2006;34:83-92 CrossRef Medline

4. Lehnert BE, Rahbar H, Relyea-Chew A, et al. Detection of ventricular shunt malfunction in the ED: relative utility of radiography, CT, and nuclear imaging. Emerg Radiol 2011;18:299-305 CrossRef Medline

5. Paulsen AH, Lundar T, Lindegaard KF. Twenty-year outcome in young adults with childhood hydrocephalus: assessment of surgical outcome, work participation, and health-related quality of life. $J$ Neurosurg Pediatr 2010;6:527-35 CrossRef Medline

6. Reddy GK. Ventriculoperitoneal shunt surgery and the incidence of shunt revision in adult patients with hemorrhage-related hydrocephalus. Clin Neurol Neurosurg 2012;114:1211-16 CrossRef Medline

7. Goeser CD, McLeary MS, Young LW. Diagnostic imaging of ventriculoperitoneal shunt malfunctions and complications. Radiographics 1998;18:635-51 CrossRef Medline

8. Madsen MA. Emergency department management of ventriculoperitoneal cerebrospinal fluid shunts. Ann Emerg Med 1986;15:133043 CrossRef CrossRef Medline

9. McNatt SA, Kim A, Hohuan D, et al. Pediatric shunt malfunction without ventricular dilatation. Pediatr Neurosurg 2008;44:128-32 CrossRef Medline

10. Zhang H, Peng J, Hao X, et al. A simple and reliable method for the diagnosis of ventriculoperitoneal shunt malfunction. World Neurosurg 2017;103:355-59 CrossRef Medline

11. Desai KR, Babb JS, Amodio JB. The utility of the plain radiograph "shunt series" in the evaluation of suspected ventriculoperitoneal shunt failure in pediatric patients. Pediatr Radiol 2007;37:452-56 CrossRef Medline

12. Griffey RT, Ledbetter S, Khorasani R. Yield and utility of radiographic "shunt series" in the evaluation of ventriculo-peritoneal shunt malfunction in adult emergency patients. Emerg Radiol 2007; 13:307-11 CrossRef Medline

13. Berrington de Gonzalez A, Mahesh M, Kim KP, et al. Projected cancer risks from computed tomographic scans performed in the United States in 2007. Arch Intern Med 2009;169:2071-77 CrossRef Medline

14. Pearce MS, Salotti JA, Little MP, et al. Radiation exposure from CT scans in childhood and subsequent risk of leukaemia and brain tumours: a retrospective cohort study. Lancet 2012;380:499-505 CrossRef
15. Boyle TP, Paldino MJ, Kimia AA, et al. Comparison of rapid cranial MRI to CT for ventricular shunt malfunction. Pediatrics 2014;134: e47-54 CrossRef Medline

16. Algin O, Hakyemez B, Parlak M. The efficiency of PC-MRI in diagnosis of normal pressure hydrocephalus and prediction of shunt response. Acad Radiol 2010;17:181-87 CrossRef Medline

17. Dixon GR, Friedman JA, Luetmer PH, et al. Use of cerebrospinal fluid flow rates measured by phase-contrast MR to predict outcome of ventriculoperitoneal shunting for idiopathic normal-pressure hydrocephalus. Mayo Clin Proc 2002;77:509-14 CrossRef Medline

18. Alperin N, Lee S, Macedo L, et al. Direct visualization and quantitation of CSF flow in shunts. Proc Intl Soc Mag Reson Med 2010;18

19. Zhang H, Zhang J, Peng J, et al. The diagnosis of ventriculoperitoneal shunt malfunction by using phase-contrast cine magnetic resonance imaging. J Clin Neurosci 2019;64:141-44 CrossRef Medline

20. Algin O, Hakyemez B, Parlak M. Phase-contrast MRI and 3D-CISS versus contrast-enhanced MR cisternography for the detection of spontaneous third ventriculostomy. J Neuroradiol 2011;38:98-104 CrossRef Medline

21. Casselman JW, Kuhweide R, Ampe W, et al. Pathology of the membranous labyrinth: comparison of T1-and T2-weighted and gadolinium-enhanced spin-echo and 3DFT-CISS imaging. AJNR Am J Neuroradiol 1993;14:59-69 Medline

22. Yousry I, Camelio S, Schmid U, et al. Visualization of cranial nerves I-XII: value of 3D CISS and T2-weighted FSE sequences. Eur Radiol 2000;10:1061-67 CrossRef Medline

23. Blitz AM, Choudhri AF, Chonka ZD, et al. Anatomic considerations, nomenclature, and advanced cross-sectional imaging techniques for visualization of the cranial nerve segments by MR imaging. Neuroimaging Clin 2014;24:1-15 CrossRef Medline

24. Doll A, Christmann D, Kehrli P, et al. Contribution of 3D CISS MRI for pre-and post-therapeutic monitoring of obstructive hydrocephalus. J Neuroradiol 2000;27:218-225 Medline

25. Elkafrawy F, Reda I, Elsirafy M, et al. Three-dimensional constructive interference in steady state sequences and phase-contrast magnetic resonance imaging of arrested hydrocephalus. World Neurosurg 2017;98:296-302 CrossRef Medline

26. Whitfield PC, Guazzo EP, Pickard JD. Safe removal of retained ventricular catheters using intraluminal choroid plexus coagulation. $J$ Neurosurg 1995;83:1101-02 CrossRef Medline

27. Chambi I, Hendrick EB. A technique for removal of an adherent ventricular catheter. Pediatr Neurosci 1988;14:216-17 CrossRef Medline

28. Handler MH. A complication in removing a retained ventricular catheter using electrocautery. Pediatr Neurosurg 1996;25:276 CrossRef Medline

29. Mavridis IN, Mitropoulos A, Mantas C, et al. Delayed intraventricular hemorrhage following a ventriculoperitoneal shunt placement: exploring the surgical anatomy of a rare complication. Case Rep Med 2017;2017:3953248 CrossRef Medline

30. Becker DP, Nulsen FE. Control of hydrocephalus by valve-regulated venous shunt: avoidance of complications in prolonged shunt maintenance. J Neurosurg 1968;28:215-26 CrossRef Medline

31. Brownlee RD, Dold ON, Myles ST. Intraventricular hemorrhage complicating ventricular catheter revision: incidence and effect on shunt survival. Pediatr Neurosurg 1995;22:315-20 CrossRef Medline

32. Collins P, Hockley AD, Woollam DH. Surface ultrastructure of tissues occluding ventricular catheters. J Neurosurg 1978;48:609-13 CrossRef Medline

33. Singh D, Saxena A, Jagetia A, et al. Endoscopic observations of blocked ventriculoperitoneal (VP) shunt: a step toward better understanding of shunt obstruction and its removal. $\mathrm{Br} J$ Neurosurg 2012;26:747-53 CrossRef Medline

34. Calayag M, Paul AR, Adamo MA. Intraventricular hemorrhage after ventriculoperitoneal shunt revision: a retrospective review. PED 2015;16:42-45 CrossRef Medline 